\title{
Psicanálise no tratamento multidisciplinar e cirúrgico da obesidade mórbida: estudo de caso'
}

\author{
Psychoanalysis in the multidisciplinary and \\ surgical treatment of morbid obesity: \\ a case study
}

Pedro Belarmino Garrido*2 Ivonise Fernandes da Motta*3

\begin{abstract}
O objetivo do estudo é avaliar o processo psicoterapêutico de abordagem psicanalítica kleiniana como contribuição na melhoria da saúde de pacientes submetidos a cirurgia bariátrica. $O$ método é de estudo de caso baseado na análise de vinheta clínica, acompanhado de levantamento bibliográfico. Analisaram-se trechos de conversas do processo psicoterapêutico de uma mulher obesa de 53 anos que procurou uma instituição dedicada ao tratamento cirúrgico da obesidade grave com enfoque multiprofissional. Após diagnóstico de obesidade mórbida, foi efetuada uma avaliação psicológica inicial. Como extensão, seguiu-se o processo psicoterapêutico de abordagem psicanalítica com frequência de uma vez por semana, passando depois a duas vezes. Dois meses após o primeiro encontro, a paciente submeteu-se à cirurgia bariátrica. A psicoterapia já tem a duração de três anos. Como resultado, a paciente tornou-se mais capaz de entrar em contato com o sentimento de desamparo associado ao fator destrutividade, que aparece em cenas narrativas de vingança, inveja e ciúme. Concluiu-se que

*1 O estudo completo, de autoria do primeiro autor, com orientação da coautora, será apresentado como dissertação de mestrado ao Departamento de Psicologia Clínica do Instituto de Psicologia da Universidade de São Paulo - USP.

*2, 3 Universidade de São Paulo - USP (São Paulo, SP, Brasil).
\end{abstract}




\section{ARTIGOS}

o processo psicanalítico se mostrou efetivo: a paciente adquiriu mais condições de preservar suas redes afetivas constituintes, e tornou-se menos vulnerável à ansiedade e impulsividade, favorecendo a permanência da redução da obesidade e evitando a formação de outras situações de padecimento, como o alcoolismo. Essas observações confirmam algumas referências já apontadas na literatura.

Palavras-chave: Obesidade mórbida, cirurgia bariátrica, processos psicoterapêuticos, psicanálise

\section{Introdução}

O Ministério da Saúde do Brasil (MSB) divulgou recentemente dados preocupantes que revelam o aumento significativo de obesos no país. A prevalência da doença passou de 11,8\% em 2006 para 19,8\% em 2018 (MSB, 2019). A Organização Mundial de Saúde (OMS) aponta a obesidade como um dos maiores problemas de saúde pública no mundo. A projeção é que em 2025 cerca de 2,3 bilhões de adultos estejam com sobrepeso, e mais de 700 milhões, obesos (ABESO, 2016).

A OMS define a obesidade como um excesso de tecido adiposo no organismo e a compreende como uma doença desencadeada por múltiplos fatores inter-relacionados, que incluem os hormonais, hereditários, psíquicos, nutricionais e sociais. A classificação mais comum baseia-se no Índice de Massa Corpórea (IMC), que se obtém dividindo o peso (em quilogramas) pelo quadrado da altura (em metros) e no nível de prejuízo à saúde associado (BVS, 2020). A obesidade grau II (IMC entre 35 e 40 $\mathrm{kg} / \mathrm{m}^{2}$ ) que já implica afecções graves associadas e a obesidade grau III (IMC maior ou igual a $40 \mathrm{~kg} / \mathrm{m}^{2}$ ) são denominadas de obesidade mórbida. Nessa situação observa-se uma grande resistência aos tratamentos clínicos baseados em dietas, exercícios e medicamentos. E esses pacientes têm uma taxa de mortalidade muito aumentada (250\%) quando comparados a não obesos (Mancini, 2002). 
Um estudo realizado pela Universidade da Carolina do Norte sobre a COVID-19 apresentou uma nova evidência preocupante: o fato de ser obeso, com o IMC acima de $30 \mathrm{~kg} / \mathrm{m}^{2}$, aumenta em $113 \%$ a chance de internação hospitalar em função dessa infecção; em $74 \%$ o risco de necessidade de cuidados intensivos e em $48 \%$ o risco de morte. A pesquisa alerta também para a possibilidade de a vacina não ser tão eficiente em pessoas obesas (Popkin et al., 2020). A cirurgia bariátrica tornou-se uma ferramenta potente para minimizar as doenças oriundas do excesso de peso e diminuir a vulnerabilidade do paciente frente à COVID-19.

Segundo a Sociedade Brasileira de Cirurgia Bariátrica e Metabólica (SBCBM), a assistência ao paciente após a cirurgia deve contar com equipes de nutrição, clínica médica e psicologia (SBCBM, 2020). É nesse contexto que este estudo busca inserção, corroborado pelos resultados da revisão que identificou a escassez de trabalhos psicanalíticos que abordam os temas de obesidade e cirurgia bariátrica (Catharin, Campos, \& Bocchi, 2020).

Passamos a introduzir alguns conhecimentos básicos relacionados com a obesidade, cirurgia bariátrica e abordagem psicanalítica terapêutica.

\section{Obesidade mórbida e cirurgia bariátrica}

A partir do uso do método psicanalítico, Altobelli e Motta (2018) apresentam o seguinte resultado: paciente com $\mathrm{IMC}=44 \mathrm{~kg} / \mathrm{m}^{2}$ perdeu mais de 40 $\mathrm{kg}$ em três anos e meio de análise. O paciente também foi tratado por nutricionista. A alteração do peso esteve associada a uma mudança de funcionamento psíquico definido na linha de pesquisa como psycho change, referenciando o conceito criado pela psicanalista kleiniana Betty Joseph.

$\mathrm{Na}$ área médica e nutricional, também há pesquisas que revelam resultados positivos no tratamento da obesidade mórbida. Entretanto, a redução do peso corporal ao redor de $25 \mathrm{~kg} / \mathrm{m}^{2}$ (saudável) seria um resultado ideal e raramente atingível na prática (Mancini et al., 2010).

Estudos mostram que o tratamento cirúrgico é mais adequado do que os tratamentos clínicos para pacientes que sofrem de obesidade severa (Picot et al., 2009). A cirurgia bariátrica promove diminuição da obesidade por meio de alterações cirúrgicas na anatomia do aparelho digestivo que reduz o volume de alimentos que o indivíduo é capaz de ingerir e/ou diminui a capacidade de absorção desses alimentos. Assim alcança-se o controle de doenças associadas como dislipidemia, hipertensão arterial, diabetes mellitus tipo 2 (Silva et al., 
2016; Wu et al., 2016) e a redução da taxa de morte de doenças cardiovasculares em longo prazo (Sjöström et al., 2012; Eliasson et al., 2015).

O estudo prospectivo sueco Swedish Obese Subjects (SOS) promoveu informações claras que sustentam que o tratamento cirúrgico é mais efetivo em relação ao clínico, e mais eficaz na manutenção da redução de peso e diminuição das doenças e mortalidade (Sjöström, 2012). Nesse estudo, dos 2037 pacientes que seguiram tratamento clínico, a média de perda de peso após 20 anos de acompanhamento foi de 1\%. Como toda a média, é possível que encontremos pontualmente resultados bons, mas que se tornam não significativos quando analisados em larga escala. Já em relação aos 2010 pacientes que realizaram a cirurgia bariátrica, a média da perda de peso após 20 anos de acompanhamento foi significativamente maior nos três tipos de cirurgia avaliadas. Destaque para a cirurgia de by pass gástrico, com $26 \%$ de média de perda de peso. O resultado da pesquisa revela que essa redução ponderal nos operados, e a manutenção proporcional dessa perda de peso ao longo do tempo, estão correlacionadas com a redução da mortalidade. Destaque para a diminuição da incidência de diabetes, infarto do miocárdio, acidentes vasculares encefálicos e de câncer. Esses dados estatísticos do SOS não evidenciam casos individuais de sucesso de tratamento clínico, bem como casos de resultados insatisfatórios dos tratamentos cirúrgicos. Falamos, por exemplo, de minorias que se tornam alcoolistas ou que voltam a se deparar com a obesidade grave ao longo do pós-cirúrgico: um ou dois pacientes de cada dez operados reincidem em obesidade grave entre cinco e dez anos depois da operação (Tinoco \& El Kadre, 2012).

Nos casos de recidiva após cirurgia bariátrica, a literatura médica dá ênfase às questões psicológicas correlacionadas ao escasso comprometimento dos pacientes nos cuidados alimentares e nos cuidados que envolvem autopromoção de bem estar e de atividades físicas cotidianas (Bradley et al., 2016). Já em relação ao alcoolismo, pesquisas recentes confirmam a preocupação da comunidade científica com o uso excessivo de álcool em alguns pacientes que se submeteram a cirurgia bariátrica (Blackburn, 2017). Nesse caso, o paciente pôde realizar uma troca direta de angústia-comida ou excitabilidade-comida para angústia-bebida ou excitabilidade-bebida, ficando mais vulnerável a se tornar alcoólatra.

Nem sempre os determinantes psicológicos como a compulsão alimentar e distúrbio de ansiedade associados à ingestão não equilibrada de alimentos, estão presentes na constituição do quadro de obesidade mórbida. Sendo a obesidade uma doença multifatorial, aspectos hereditários, hormonais e sociais 
podem ser mais significativos na formação do quadro do que os psicológicos. Portanto, para aqueles que apresentarem determinantes psicológicos na constituição do quadro de obesidade mórbida a esperança de readquirir a saúde pode se frustrar se o cuidado com a saúde mental for negligenciado.

Os casos de insucesso cirúrgico apontam para a importância da avaliação psicológica anterior à realização do procedimento bariátrico. É importante investigar o nível de vulnerabilidade psíquica do paciente capaz de promover o retorno de prejuízos físicos e mentais. Uma vez identificado o estado de vulnerabilidade, a função da equipe multiprofissional é indicar tratamento psicológico e/ou psiquiátrico.

\section{A abordagem psicanalítica no processo terapêutico}

Com as devidas delimitações do campo cirúrgico e psicológico, cabe analisar como a psicanálise se insere no tratamento multidisciplinar de obesidade mórbida. No que diz respeito a essa questão, especificamente em relação aos pacientes que sofrem de compulsão alimentar e distúrbio de ansiedade, vale a pena nos debruçarmos sobre o conceito de pulsão de morte (Freud, 1920/1996). Freud investigou processos psíquicos que se apresentavam repetidamente como uma encenação de um sofrimento que não podia, num primeiro momento, ser verbalizado. Nesse processo mais primitivo a quantidade de excitação que atravessa o aparelho psíquico flui livremente, exigindo uma descarga imediata das tensões (pulsão de morte). E no mais elaborado, a tensão e excitabilidade que atravessam o aparelho psíquico estabelecem ligações com representações psíquicas (pulsão de vida).

A consolidação do dualismo pulsional (Freud, 1920/1996) ofereceu instrumentais teóricos e técnicos bastante utilizados nos tratamentos atuais de compulsões (comida, sexo, jogo, droga, compras), distúrbio de ansiedade, síndrome do pânico e síndrome de burnout (Schwartzman, 2004). Nesses casos, de forma repetitiva a pulsão alcança sua finalidade (satisfação) sem a mediação de elementos simbólicos. A satisfação se dá essencialmente por meio de atuações motoras associadas a um objeto, funcionamento típico das compulsões, ou por meio de manifestações psicossomáticas, como as palpitações cardíacas presentes na síndrome do pânico. Nesses quadros clínicos o aparelho psíquico funciona numa espécie de curto-circuito entre o impulso e a ação, de maneira que o processamento psíquico fica isolado da operação (Mayer, 2001). 


\section{ARTIGOS}

Os referenciais kleinianos sustentam a compreensão sobre um funcionamento menos elaborado que, num estado de insuficiência para lidar com as vicissitudes da vida, liberta o aparelho psíquico do excesso de ansiedade, promovendo cisões e projeções. Como consequência, as diversas redes de afetos que nos constituem ficam desconectadas umas das outras e a capacidade de criar símbolos fica empobrecida (Cintra \& Ribeiro, 2018).

E sua experiência clínica com crianças pequenas (Klein, 1932/1997) revela que o eu primitivo reage à experiência de frustração com fúria $\mathrm{e}$ ansiedade. Em fantasia o eu primitivo faz da mãe uma espécie de bruxa má que irá devorá-lo com a mesma característica da sua fúria sádica inicial (Klein, 1932/1997). Trata-se de uma identificação por projeção de partes excindidas do eu. Ou seja, cindidas e postas para fora do eu e direcionadas para dentro do objeto, que passa a adquirir na fantasia do eu primitivo essas qualidades sádicas e destrutivas (Klein, 1946/1991a). E quando tudo parece caótico e persecutório, eis que surgem outras qualidades circunscritas nesse local de travessia de afetos entre a criança e a mãe: gratificação, satisfação e prazer. Surge nesse contraponto a esperança de que é possível superar o horror cruel da indigesta frustração. Portanto, temos uma primeira organização de mundo que é confirmada e remarcada com as sucessivas experiências de gratificação e frustração. A mãe é capaz de influenciar nessa organização, evidentemente. Uma mãe que, ao lidar com o choro perturbador do filho, apresentar de forma ansiosa o alimento pode mais atrapalhar do que ajudar, porque o bebê sentirá a ansiedade da mãe e isso intensifica seu mal-estar em vez de diminuí-lo. A capacidade da mãe de suportar o mal-estar do bebê e intuitivamente estar à disposição para que o bebê possa criar novamente um estado de relação gratificante potencializa um estado de esperança, reafirmando a crença no bom. Isso favorece o início de processos de integração.

Conforme o bebê vive as sucessivas experiências de frustração e gratificação, como descrito, ele projeta (projeção) no não eu o mal-estar associado à fúria; toma para si (introjeção) a característica de generosidade da experiência terna vivida com a mãe e, dessa forma, cria um mundo mental próprio em que o eu e o não eu apresentam características misturadas ou trocadas. Tal mistura vai, na continuidade desse processo de projeção e introjeção, desfazendo-se e o eu passa a apreender as experiências de vida de uma maneira mais fidedigna em relação à realidade. Surge, portanto, um momento em que se constata o firme estabelecimento do objeto bom no núcleo do ego, o que permite que lentamente o aspecto destrutivo se amenize e surja a oportunidade do objeto ser apreendido não de forma cindida (mãe boa e mãe má), mas de forma total 
e integrada. Isso implica a percepção de que a mãe que cuida e é generosa é a mesma que falha. Associado a isso, o eu se percebe como um ser diferente do não eu, e inaugura uma experiência emocional madura de preocupação e cuidado com o objeto amado. Melanie Klein nomeia esse estado maduro de posição depressiva (Klein, 1935/1996).

A entrada na posição depressiva é o ponto de maior aproximação com o campo de funcionamento mental que Freud nomeava de representacional (Freud, 1920/1996). A representação psíquica só pode ser inscrita no aparelho psíquico quando a organização mental constrói uma relação objetal com um objeto total e integrado, ou seja, com a mãe (e não com a mãe boa e a mãe má). O nível de ansiedade diminui e abre-se espaço para o desenvolvimento simbólico propriamente dito.

Para Klein (1935/1996a), o psiquismo humano normal infantil e adulto oscila entre estados mais integrados (posição depressiva) e estados de não integração repletas de projeções e cisões (posição esquizoparanoide).

O pressuposto básico dos processos psicanalíticos envolve o desenvolvimento de um aparelho psíquico que se organize essencialmente de forma integrada, oferecendo amplos ganhos simbólicos ao paciente. Isso diminui a vulnerabilidade em relação à ação da pulsão de fluxo livre ou pulsão de morte (Freud) e à ação dos mecanismos de projeção e cisão (Klein). Para um paciente que se submeteu à cirurgia bariátrica e sofria de compulsão alimentar, ou distúrbio de ansiedade associado à ingestão não equilibrada de alimentos, isso significa poder se organizar de forma mais integrada e ficar menos vulnerável a se deparar novamente com a obesidade (recidivas) ou a ingerir bebida alcoólica em excesso, por exemplo.

Relevante destacar que, do ponto de vista metodológico, a psicanálise se firmou no campo das ciências humanas. $O$ método psicanalítico não se caracteriza por coleta de dados quantitativos, generalizáveis, com o objetivo de esgotar todo o saber possível sobre o tema em questão. O instrumento metodológico utilizado pelo psicanalista em sua clínica é a atenção flutuante, modo peculiar de escutar o sujeito que fala a respeito de seu sofrimento. É através dela, junto com a associação livre do paciente, que se constrói um registro lógico e simbólico, oferendo a possibilidade de se ter acesso ao sentido expresso daquilo que é levado de forma adoecida e inconsciente pelo sujeito.

Circunscrevendo-se no campo da obesidade mórbida, este estudo enuncia articulações entre teoria e experiência clínica relacionadas com cirurgia bariátrica, ressaltando os conceitos desenvolvidos pela psicanalista Melanie Klein. 


\section{ARTIGOS}

O objetivo é compreender como o processo psicoterapêutico de abordagem psicanalítica contribui para a melhoria da saúde de pacientes que se submetem à cirurgia bariátrica. Busca investigar se há uma diminuição das ações não verbais e impulsivas a partir da intervenção psicanalítica.

\section{Metodologia}

O delineamento da pesquisa é de estudo de caso, desenvolvido com base na análise de vinheta clínica. Utilizaram-se os conceitos psicanalíticos de Freud e Melanie Klein para articular a discussão exposta com a análise de material clínico. A abordagem da análise dos dados é, portanto, qualitativa. O projeto de pesquisa foi aprovado pelo Comitê de Ética.

Foram analisados trechos do processo psicoterapêutico de abordagem psicanalítica de uma mulher de 53 anos de idade, que apresentava IMC $=42 \mathrm{~kg}$ / $\mathrm{m}^{2}$ (105,4 quilogramas e 1,58 metros de altura) e doenças associadas: dispneia ao esforço (aparelho respiratório), histórico de trombose venosa profunda (aparelho circulatório), condromalácia patelar (aparelho osteomuscular) e incontinência urinária (aparelho geniturinário). A equipe médica identificou o quadro de obesidade grave e indicou intervenção cirúrgica como tratamento. Além da avaliação médica foi realizada avaliação nutricional e psicológica.

A nutricionista confirmou a existência de grande excesso de gordura no organismo e obesidade de grau III. Na avaliação clínica foram confirmados os dados acima referidos, e examinado o risco de novo evento tromboembólico no período operatório e recomendados os cuidados adequados.

A avaliação psicológica também foi realizada com o psicólogo da própria equipe. Do ponto de vista psicológico a paciente apresentava clareza e autonomia na escolha de se submeter ao procedimento cirúrgico proposto. Isso significa que a paciente compreendia bem os riscos do ato cirúrgico em si; a necessidade de mudança dos hábitos alimentares e sua responsabilidade no que se refere aos retornos com a equipe multiprofissional (cirurgiões, endocrinologistas, clínicos gerais, nutricionistas e psicólogo ou psiquiatra) por toda a vida, em especial nos dois primeiros anos. A avaliação psicológica também revelou ausência de histórico de uso de drogas ilícitas ou alcoolismo, ausência de quadros demenciais graves e ausência de quadros psicóticos graves em curso. Não havia, portanto, contraindicação psicológica para a realização da cirurgia. Mas foi indicado início de psicoterapia, já que a paciente sofria de distúrbio de ansiedade associado à ingestão impulsiva e 
desordenada de alimentos. Isso poderia torná-la vulnerável a se deparar com a obesidade novamente ao longo de sua evolução futura, ou a ter outras sintomatologias associadas à ansiedade.

Durante o processo de avaliação psicológica a paciente formulou uma demanda de psicoterapia fundamentada na percepção de que havia uma série de situações ansiógenas em sua vida que sobrecarregavam o campo alimentar. Também se mostrou intrigada com o fato de ter atingido peso tão elevado. Após a devolutiva da avaliação psicológica iniciou-se o processo psicoterapêutico com o mesmo psicólogo. O método utilizado foi o psicanalítico. $\mathrm{O}$ tratamento teve início com frequência de uma vez por semana, passando a duas vezes após um ano de atendimento. A operação bariátrica foi realizada dois meses após o primeiro atendimento psicológico. O processo psicoterapêutico já dura três anos. O nome da paciente foi representado no texto pela letra Z. Características pessoais consideradas não relevantes para o estudo foram alteradas para garantir o sigilo em relação à paciente e aos envolvidos.

Como cheguei a pesar tanto? - se interroga a paciente. A resposta a essa questão se constrói com o uso do método. Não será uma resposta pronta e acabada, mas a proposta é oferecer como resultado uma transformação: um aparelho psíquico que promove ganhos em significação e construção de sentido, rompendo com aquilo que inicialmente fazia engolir alimentos de forma impulsiva e desordenada. Ou seja, o que é dito pela paciente e escutado pelo analista está inserido no registro simbólico e diz respeito àquilo que se sonha, às lembranças rememoradas e à narrativa das experiências de vida.

\section{Estudo de caso}

A paciente Z, ao longo do processo de avaliação psicológica pré-operatória, iniciou com a seguinte questão, sua demanda de análise: "Como cheguei a pesar tanto?" Nas primeiras sessões preocupava-se com questões vinculadas à cirurgia bariátrica e sua recuperação: expectativas em relação ao agendamento da cirurgia e desafios da dieta líquida e sólida no pós-operatório, por exemplo. Mas logo começou a intercalar falas referentes à perda de sua mãe e conflitos no casamento (no momento quase simultâneo à perda da mãe, seu marido lhe comunicou ser pai de uma menina, fruto de um relacionamento extraconjugal). Klein sugere que no processo de luto urge a necessidade de o psiquismo se reestabelecer e reintegrar o mundo interno. Em última instância, em reconquistar a posição depressiva. Algumas pessoas 
apresentam dificuldade nessa reconquista, reativando ansiedades persecutórias e mecanismos de cisão e projeção (Klein, 1940/1996c). Z justamente entendia que seu peso havia subido muito em função do sofrimento que viveu nesse momento de sua vida, que compensava com ingestão inadequada de alimentos. Situações de muito sofrimento eram revividas em sessão cada vez que mencionava uma dessas situações, que se apresentavam misturadas pela lógica simbólica e cronológica.

No entanto, lentamente passou a trazer questões de seu relacionamento extraconjugal, que ela mantinha há anos. Com esse homem ela viveu em parte uma vingança, assim por ela nomeada, e também viveu a expectativa de se separar do marido e se casar novamente. Em psicoterapia ficou mais claro esse duplo sentido do amante. Além disso pôde perceber, não sem sofrimento, que seu amante não abandonaria a mulher e filhos para se casar com ela.

À medida que ia tecendo um novo sentido para os seus relacionamentos conjugal e extraconjugal, $Z$ foi ficando mais leve e menos ansiosa. Neste novo tecido, fez sentido para ela encerrar seu relacionamento extraconjugal e buscar um parceiro com o qual pudesse viver de forma mais integrada seu dia a dia, uma pessoa que pudesse viver com ela com seus defeitos, limitações e qualidades. Ela escolheu seu marido para ser esse parceiro. Abordando a problemática com ele, encontrou grandes distanciamentos entre os dois, alguns que considera difícil reverter, como, por exemplo, conhecer a filha do marido. Apesar das dificuldades, aproximações construtivas se efetivaram e o casal começou a se reaproximar.

Num outro momento do processo psicoterapêutico, interroga-se sobre o aspecto do excesso alimentar: "Engraçado, estou aqui há quase três anos com você e a gente não fala sobre comida, né?! Por que, hein?! Vim aqui porque você é o especialista nisso e não conversamos sobre isso" (rindo). O psicoterapeuta respondeu: "Porque o que se fala não se engole". Metabolizando a resposta, que se apresentou de forma indigesta para $Z$, ficou claro para ela que as situações que geram sofrimento, conflitos e tensões são verbalizadas na psicoterapia, gerando produção de sonhos, de lembranças encobridoras e associações livres, promovendo construção de sentido. "O que se fala não se engole" resume um trabalho psíquico que traz um ganho de significação para aquilo que originalmente era um mal-estar. Ou seja, quando ela dá forma ao mal-estar, quando dá sentido a ele, não precisa engoli-lo ou se livrar dele imediatamente em atos dissipatórios correspondentes ao destino da pulsão de morte, tal qual postulado por Freud (1920/1996). Observações não exatamente iguais são indicadas por Betty Joseph ao trazer o conceito de psycho change. 
Considerando uma mudança psíquica duradoura em termos de movimento em direção à posição depressiva, o paciente sustenta uma maior capacidade de integração do self e organiza suas relações de objeto de forma total e mais realista (Joseph, 1992).

A seguir, na continuidade da sessão, $\mathrm{Z}$ voltou à questão: Como cheguei a pesar tanto? "Estava pensando que sempre fui obesa desde pequena. [...]Não sei por que eu sempre fui gordinha. Por que diabo eu sempre me via gordinha, era gordinha, sofria gordinha? Na casa dos meus pais, minha mãe cozinhava até, mas meu pai sempre foi do carboidrato, do pão, do macarrão... Então até tinha a comida saudável, mas eu, meus irmãos também, eu acho, beliscávamos uma bolacha aqui, outra acolá, por exemplo. Me lembro agora de que eu acordava às vezes para ir ao banheiro de madrugada e depois passava na cozinha e comia uma bolacha ou outra, não era nada compulsivo, e voltava para a cama. Não precisava comer, mas comia. Não era muito, mas era. Fui ganhando peso gradativamente. Quando minha mãe faleceu eu já era bem gordinha. Mas ganhei mais peso sim, depois que ela se foi..." O que confirma a hipótese de que $\mathrm{Z}$ teve mais dificuldades de reintegrar seu mundo interno a partir da perda da mãe. Trouxe a seguir uma foto para expressar suas tendências afetivas. Ela devia ter em torno de cinco anos de idade. A cena da foto se dava num banco de jardim. Ela estava num canto do banco, parecia meio espremida nesse canto, apesar de todos caberem de forma espaçosa. Ao seu lado vinha seu irmão, o mais velho, e a seguir a mãe, no meio da cena, sorrindo e com as duas mãos apoiadas no seu próprio joelho. Um espaço e então aparece a sua irmã sendo abraçada pelo pai. A irmã com um sorriso discreto, mas claramente satisfeita por estar junto ao pai. E o pai dando risada, como se estivesse brincando com a filha. "Eu era uma boa menina, parecia sempre que estava tudo bem comigo, eu até estava com um leve sorriso nessa foto. Mas eu estava sofrendo. Veja ela lá quase deitada no colo do meu pai (fala com ódio)?! E eu ali sozinha, paralisada do outro lado do banco". O discurso repleto de ansiedade de $\mathrm{Z}$ faz emergir seu traço mais primitivo, em que o fator destrutividade se revela através do ciúme e da inveja. Melanie Klein justamente afirma que a ansiedade se origina do impulso destrutivo constitucional direcionado ao objeto. O medo de ficar só, de ser abandonada pela mãe, aparece muito claramente no material das análises de crianças pequenas, em especial de meninas. "Mas esse medo, creio, tem uma origem mais profunda. Está baseado nos impulsos agressivos da criança contra a mãe e nos seus desejos de matar a mãe e de roubá-la, desejos oriundos dos estágios iniciais do conflito edipiano" (Klein, 1932/1997, p. 51). 


\section{ARTIGOS}

Curiosamente, nessa mesma sessão, $Z$ trouxe também uma foto de sua pré-adolescência. Dançava com o pai e o pai ria de alegria por estar dançando com ela. $\mathrm{O}$ curioso foi que a raiva, o ciúme e a inveja foram tamanhos em relação à irmã, que ela não pôde manter vívida em sua memória essa foto alegre com o pai. Nas sessões que se sucederam ela retomou apenas a primeira imagem, do banco do jardim, e a raiva suscitada na cena. Considerando o pensamento de Klein (1957/1991b), diríamos que nesse momento $\mathrm{Z}$ estava, através do ciúme, elaborando impulsos destrutivos direcionados ao objeto originário, a mãe. Assim, em certa medida, o ciúme tira de foco a inveja causada pelo desejo edípico da menina de tomar o lugar da mãe e possuir e cuidar dos bebês que o pai amado dá à mãe. Para Klein, o ciúme é mais fácil de ser digerido psiquicamente, pois gera menos culpa e ansiedade em relação à inveja primária. A inveja carrega uma intensidade de destruição maior em relação ao objeto originário, gerando ansiedade persecutória, cisões e projeções. Através do ciúme, $\mathrm{Z}$ claramente desloca o fator destrutividade para a irmã, que ocupa o lugar da mãe má na cena edípica, preservando assim a mãe boa, carinhosa e generosa: "Minha mãe sempre esteve ao meu lado nos momentos difíceis. Sempre senti ela presente". Uma presença idealizada, que não falta. Assim era o retrato de sua mãe no início do processo.

Num outro momento, contudo, trouxe uma lembrança de uma situação de dor vivida com a mãe na praia. A família costumava passar finais de semana em um apartamento no litoral. Ela se lembra de estar comendo salgadinho no sofá, enquanto seu irmão, irmã e pai já desciam para a praia. Enquanto comia o salgadinho, esperava sua mãe. A mãe finalizou seus afazeres, saiu do apartamento, trancou a porta e foi para a praia: "Minha mãe me esqueceu dentro do apartamento. Me lembro de ter ficado no vidro gritando para as pessoas na rua dizendo que haviam me esquecido em casa". Isso significa que na rede afetiva de $\mathrm{Z}$ tornou-se possível integrar a mãe carinhosa, generosa e que sempre esteve presente com a mãe que falha e que a esquece em casa. Isso implica suportar um estado de ambivalência: o objeto de amor e o objeto faltante, depositário do ódio, é o mesmo. No estado de integração não há a necessidade de se criar cisões e projeções para alocar o ódio. O processo psicoterapêutico facilitou a possibilidade de integrar as imagos maternas, desconstruindo idealizações e cisões. Neste sentido $Z$ fortalece sua capacidade de construção simbólica, situando-se num estado psíquico de concernimento conforme a posição depressiva postulada por Klein (1935/1996a).

A propósito, numa sessão mais recente em função da hospitalização do pai, Z, preocupada com seu bem-estar, utilizou seus recursos para lhe oferecer 
as melhores condições de cuidado possível, de uma maneira bastante solidária. Na sessão descreveu uma imagem como se fosse uma fotografia, em que ela estava abraçada ao pai, com seu irmão de um lado e sua irmã de outro. O que se destaca nessa cena era menos seu posicionamento de rivalidade em relação à irmã, no sentido de ser ela $\mathrm{Z}$ a filha que de fato abraçava o pai e mais a sua capacidade terna, generosa e cooperativa de cuidar do pai junto com os irmãos. Uma imagem de integração em que os afetos destrutivos de ciúme e rivalidade não se sobrepuseram à ternura e à capacidade de cuidar e amar.

Por fim, vale destacar a capacidade de sonhar de $\mathrm{Z}$ e narrar seus sonhos ao psicoterapeuta. Num dos sonhos traz a imagem de um quadro da empresa em que trabalhava. A área que ela dirigia foi integrada a uma outra e $\mathrm{Z}$ foi desligada da empresa, após anos de um trabalho que foi muito reconhecido. Apesar de receber da empresa uma quantia muito generosa no ato da rescisão, demonstrando o reconhecimento e valor que tem, seu sentimento sempre foi de indignação em relação a uma exclusão que para ela não fazia sentido. No sonho, no quadro figuravam o presidente da empresa, o vice-presidente e os diretores. A diretora que se tornou responsável por sua área já estava na pintura, no lugar de Z. Ela observa o quadro e vai embora do evento, incomodada. Percebe que levou jóias que não lhe pertenciam. Ficou preocupada de acharem que ela havia roubado as jóias e começa a telefonar para a área de segurança para devolvê-las, mas não consegue falar com ninguém. Z, utilizando de um recurso simbolicamente sofisticado, que é a produção onírica, expressa seu sentimento de se sentir roubada e de reagir à sua fúria retirando do outro o seu valor (as jóias). Melanie Klein sustenta que o eu-primitivo voraz suga o seio da mãe, mas o faz de tal forma que retira deste suas qualidades, tomando-as para si. Klein justamente fala que nesse estado psíquico o objeto interno é sentido como invejoso e malevolente. Quando isso ocorre, o objeto bom é sentido como perdido, e com ele a segurança interna. Suas observações mostraram que em qualquer estágio da vida, quando a relação com o objeto bom está seriamente perturbada - uma perturbação em que a voracidade e a inveja desempenham um papel proeminente - a segurança e a paz interna ficam deterioradas, a ansiedade se intensifica e os mecanismos de cisão e projeção entram em funcionamento (Klein, 1957/1991b). Apesar de $\mathrm{Z}$ expressar claramente a fúria em relação à dor da rejeição, que sente ainda como muito atual, ela o faz de forma elaborada. Primeiramente porque os processos de cisão e projeção são desfeitos quando o sonho é recordado e revelado a alguém — trata-se de um fenômeno associado aos processos de integração (Winnicott, 1945/2000). E, além disso, o conteúdo do sonho 
traz representações de preocupação e de segurança interna. $Z$ revela através do processo de elaboração do sonho experiências de ansiedade em relação à perda de uma posição na empresa e, num nível mais profundo, perda de um lugar no enquadramento edípico. Em relação ao dano gerado nesse objeto-empresa ao levar jóias que não eram suas, ela se utiliza da instância psíquica do segurança para promover a reparação e pacificação do conflito. Junto com o fator destrutividade, há na mente inconsciente das pessoas um movimento legítimo de restauração das lesões e feridas realizado em fantasia. Nas profundezas da mente, o desejo de pacificar as relações com as pessoas amadas está ligado à forte sensação de responsabilidade e de preocupação com elas, que se manifesta pela solidariedade genuína e pela habilidade de compreender como elas são e como se sentem (Klein, 1937/1996b).

Portanto, como resultado da intervenção psicoterapêutica de abordagem psicanalítica, $\mathrm{Z}$ adquiriu mais condições de preservar suas redes afetivas constituintes, funcionando psiquicamente de forma mais integrada e abrindo espaço para a sobreposição da expressão verbal e simbólica em detrimento da expressão não verbal, ansiógena, cindida e impulsiva. Em relação à obesidade, $\mathrm{Z}$ atingiu o peso de $71,4 \mathrm{~kg}$ em agosto de 2018 e alcançou o peso mínimo de $66,8 \mathrm{~kg}(\mathrm{IMC}=26,8 \mathrm{~kg} / \mathrm{m} 2)$, apenas ligeiramente acima do normal, mantendo-o estável até o mês de agosto de 2020, data em que completou três anos de psicoterapia. Nesse período também não usou nenhum tipo de droga ilícita e ingeriu bebida alcoólica somente de maneira pontual em situações sociais específicas. Do ponto de vista médico também houve melhora significativa do seu estado de saúde, em especial das doenças associadas à obesidade presentes no estágio anterior à cirurgia. A paciente aderiu ao tratamento multidisciplinar, o que também é resultado do fortalecimento do vínculo desenvolvido no processo psicoterapêutico, mantendo-se bem nutrida e ingerindo os suplementos nutricionais necessários. Esse é o desfecho mais desejável no tratamento cirúrgico da obesidade mórbida. Trata-se de um resultado relevante, já que a literatura aponta para uma tendência de pacientes que sofrem de distúrbio alimentar de serem resistentes à exploração de seus sintomas junto à equipe multidisciplinar, mesmo quando um mínimo de confiança foi alcançado com o psicoterapeuta e uma relação de trabalho foi bem estabelecida (Barth, 2014).

O resultado confirma também a eficácia do método psicanalítico e princípios básicos da psicanálise expressados por Altobelli \& Motta (2018) e Joseph (1992) e dados da literatura que correlacionam aspectos psíquicos com obesidade (Mancini, 2010). 
Contudo, vale destacar que o potencial do método psicanalítico neste trabalho se revela pelo estudo de um único caso clínico. Seria interessante se pudéssemos incluir maior número de articulações teórico-clínicas em pesquisas deste tipo em larga escala, em universidades ou serviços especializados que possam investir na manutenção de um grupo sólido de investigação. Eventualmente pode-se utilizar diferentes abordagens de psicoterapia nessa situação, inclusive com misturas de técnicas e até a integração de psicofármacos, conforme já referem alguns trabalhos (Barth, 2014; Connors, 2006; Zerbe, 2008).

\section{Conclusão}

Concluímos que a psicoterapia de abordagem psicanalítica se mostrou efetiva, já que a paciente adquiriu mais condições de preservar suas redes afetivas constituintes e tornou-se menos vulnerável à ansiedade e à impulsividade, favorecendo a permanência da redução da obesidade e evitando a formação de outras situações de padecimento como alcoolismo. A paciente tornou-se mais capaz de entrar em contato com o sentimento de desamparo associado ao fator destrutividade, que aparece nas cenas narradas de vingança, inveja e ciúme. No percurso do processo psicoterapêutico houve ocasiões em que essa atitude que integra e une não pôde ser mantida; mas houve claramente movimentos psíquicos de elaboração simbólica, que ainda estão em curso, que deixam a paciente menos vulnerável em relação à desconexão das diversas redes de afetos que nos constituem. E, como paciente submetida à cirurgia bariátrica, deixam-na menos vulnerável a se deparar novamente com a obesidade mórbida ou com outras situações de perda de saúde físico-mental.

Considerando as pesquisas neste campo específico de atuação, há evidências de que é por intermédio do processo de integração dos elementos psíquicos mais primitivos, elaborados no processo psicoterapêutico (recursos psicanalíticos), associado aos recursos da medicina clínica e cirúrgica, que reside a maior esperança de ajudar os pacientes que sofrem de obesidade mórbida. Os determinantes psíquicos na constituição do quadro, seja em função da compulsão alimentar, seja em função de distúrbio de ansiedade associado à ingestão desordenada de alimentos, podem ser amenizados com a psicoterapia psicanalítica. 


\section{ARTIGOS}

\section{Referências}

Altobelli, C., \& Motta, I. (2018). The clinical treatment of obesity from a psychoanalytical perspective. Journal of Health Science, 6, 243-248.

Associação Brasileira para o Estudo da Obesidade e Síndrome Metabólica (ABESO). (2016). Sbem Nacional e Abeso lançam nova campanha do Dia Mundial da Obesidade. Recuperado em 20 ago. 2020 de: $<$ https://abeso.org.br/sbem-nacionale-abeso-lancam-nova-campanha-do-dia-mundial-da-obesidade>.

Barth, F. D. (2014). Putting it all together: An integrative approach to psychotherapy with eating disorders. Psychoanalytic Social Work, 21, 19--39. DOI: 10.1080/15228878.2013.865245.

Biblioteca Virtual Ministério da Saúde do Brasil - BVS (2020). Dia mundial da obesidade. Recuperado em 29 set. 2020 de: <http://bvsms.saude.gov.br/ultimasnoticias/3134-04-3-dia-mundial-da-obesidade>.

Blackburn, A., Hajnal, A., \& Leggio, L. (2017). The gut in the brain: the effects of bariatric surgery on alcohol consumption. Addiction Biology, 22(6), 1540-1553. Doi 10.1111/adb.12436.

Bradley, L., Forman, E., Kerrigan, S., Goldstein, S., Butryn, M., Thomas, J., \& ... Sarwer, D. (2016). Project HELP: a remotely delivered behavioral intervention for weight regain after bariatric surgery. Obesity Surgery, 27, 586-598, 2017. Recuperado em 20 ago. 2020 de: <https://link.springer.com/content/pdf/10.1007/ s11695-016-2337-3.pdf>.

Catharin, V., Campos, E., \& Bocchi, J. (2020). Psicanálise, cirurgia bariátrica e obesidade: uma revisão integrativa. Revista da SBPH, 23(1), 81-94. Recuperado em 17 ago. 2020 de: <http://pepsic.bvsalud.org/scielo.php?script=sci_ arttext\&pid=S1516-08582020000100008\&lng=pt\&tlng=pt $>$.

Cintra, E., \& Ribeiro, M. (2018). Por que Klein? São Paulo, SP: Zagodoni.

Connors, M. (2006). Symptom-focused Dynamic Psychotherapy. Mahwah, NJ: The Analytic Press.

Eliasson, B., Liakopoulos, V., Franzén, S., Näslund, I., Svensson A., Ottosson, J., \& Gudbjörnsdottir, S. (2015). Cardiovascular disease and mortality in patients with type 2 diabetes after bariatric surgery in Sweden: a nationwide, matched, observational cohort study. Lancet Diabetes and Endocrinolology, 3(11), 847-54. DOI: $10.1016 / \mathrm{S} 2213-8587(15) 00334-4$.

Freud, S. (1996). Além do princípio do prazer. In Edição Standard Brasileira das Obras Psicológicas Completas de Sigmund Freud (Vol. 18). Rio de Janeiro, RJ: Imago. (Trabalho original publicado em 1920).

Joseph, B. (1992). Equilíbrio psíquico e mudança psíquica: artigos selecionados 
de Betty Joseph. Organizado por Michael Feldman e Elizabeth Bott Spillius; coordenador da ed. brasileira Elias Mallet da Rocha Barros; tradução de Belinda Haber Mandelbaum. Rio de Janeiro, RJ: Imago.

Klein, M. (1991a). Notas sobre alguns mecanismos esquizoides. In Inveja e gratidão e outros trabalhos (1946-1963). Rio de Janeiro, RJ: Imago. (Trabalho original publicado em 1946).

Klein, M. (1991b). Inveja e gratidão. In Inveja e gratidão e outros trabalhos (19461963). Rio de Janeiro, RJ: Imago. (Trabalho original publicado em 1957).

Klein, M. (1996a). Uma contribuição à psicogênese dos estados maníaco-depressivos. In Amor, culpa e reparação. Rio de Janeiro, RJ: Imago. (Trabalho original publicado em 1935).

Klein, M. (1996b). Amor, culpa e reparação. In Amor, culpa e reparação. Rio de Janeiro, RJ: Imago. (Trabalho original publicado em 1937).

Klein, M. (1996c). O luto e suas relações com os estados maníaco-depressivos. In Amor, culpa e reparação. Rio de Janeiro, RJ: Imago. (Trabalho original publicado em 1940).

Klein, M. (1997). Estágios iniciais do conflito edipiano e da formação do superego. In A psicanálise de crianças. Rio de Janeiro, RJ: Imago. (Trabalho original publicado em 1932).

Mancini, M. (2002). Noções fundamentais - diagnóstico e classificação da obesidade. In A. B. Garrido Jr. (Ed.), Cirurgia da obesidade. São Paulo, SP: Atheneu.

Mancini, M. (2010). Obesidade e doenças associadas. In M. C. Mancini et al., Tratado de obesidade. Itapevi, SP: AC Farmacêutica.

Mancini, M., Melo, E., \& Halpern, A. (2010). Farmacoterapia da obesidade: princípios gerais do tratamento. In M. C. Mancini et al., Tratado de obesidade. Itapevi, SP: AC Farmacêutica.

Mayer, H. (2001). Passagem ao ato, clínica psicanalítica e contemporaneidade. In M. Rezende Cardoso (Org.), Adolescência: reflexões psicanalíticas. Rio de Janeiro, RJ: Nau Editora.

Ministério da Saúde do Brasil - MSB. (2019). Brasileiros atingem maior índice de obesidade nos últimos treze anos. Recuperado em 26 ago. 2020 de: <https://www. saude.gov.br/noticias/agencia-saude/45612-brasileiros-atingem-maior-indice-deobesidade-nos-ultimos-treze-anos $>$.

Picot, J., Jones, J., Colquitt, J., Gospodarevskaya, E., Loveman, E., Baxter, L., \& Clegg, A. (2009). The clinical effetiveness and cost-efetiveness of bariatric (weight loss) surgery for obesity: a systematic review and economic evaluation. Health Technology and Assessment; 13(41), 1-190.215-357. Recuperado em 29 ago. 2020 de: <https://www.emerald.com/insight/content/doi/10.1108/ cgij.2010.24815aae.002/full/html $>$. 


\section{ARTIGOS}

Popkin, B., Du, S., Green, W., Beck, M., Algaith, T., Herbst C., \& ... Shekar, M. (2020). Individuals with obesity and COVID-19: A global perspective on the epidemiology and biological relationships. Obesity Reviews, 1(17). doi. org/10.1111/obr.13128.

Schwartzman, R. (2004). O conceito de recalcamento e a busca de uma metapsicologia para as novas patologias. In M. R. Cardoso, Limites. São Paulo, SP: Escuta.

Silva, C., Cohen, L., Sarmento, L., Rosa, F., Rosado, E., Carneiro, J.,... \& Magno, F. (2016). Effects of long-term Roux-En Y gastric bypass on body weight and clinical metabolic comorbidities in bariatric surgery service of a university hospital. Arquivos Brasileiros de Cirurgia Digestiva, 29(1), 20-23. doi. org/10.1590/0102-6720201600s10006.

Sjöström, L. (2012). Review of the key results from the Swedish Obese Subjects (SOS) trial - a prospective controlled intervention study of bariatric surgery. Journal of Internal Medicine, 273(3), 219-134. Doi: 10.1111/joim.12012.

Sjöström, L., Peltonen, M., Jacobson, P., Sjöström, C., Karason, K., Wedel, H.,... \& Carlsson, L. (2012). Bariatric surgery and long-term cardiovascular events. JAMA; 307(1), 56-65. doi:10.1001/jama.2011.1914.

Sociedade Brasileira de Cirurgia Bariátrica e Metabólica - SBCBM (2020). Obesidade é o principal fator de risco para COVID-19. Recuperado de: $<$ https://www.sbcbm.org.br/cirurgias-bariatricas-caem-na-pandemia-masobesidadecontinua-sendo-maior-fator-de-risco-para-covid-19/>.

Tinoco, A., El Kadre, L. (2012). Como explicar a perda de peso nas diferentes técnicas de cirurgia bariátrica. In M. T. C. Diniz et al., Cirurgia bariátrica e metabólica: a abordagem multidisciplinar. São Paulo, SP: Atheneu.

Winnicott, D. (2000). O desenvolvimento emocional primitivo. In Da pediatria à psicanálise: obras escolhidas. Rio de Janeiro, RJ: Imago. (Trabalho original publicado em 1945).

Wu, G., Cai, B., Yu, F., Fang, Z., Fu, X., Zhou, H., ... \& Tian, Z. (2016). Metaanalysis of bariatric surgery versus non-surgical treatment for type 2 diabetes mellitus. Oncotarget, 7(52), 87511-22. doi: 10.18632/oncotarget.11961.

Zerbe, K. (2008). Integrated treatment of eating disorders: Beyond the body betrayed. New York, NY: W.W. Norton \& Co. 


\section{Resumos}

(Psychoanalysis in the multidisciplinary and surgical treatment of morbid obesity: a case study)

We assessed the psychotherapeutic process based on a Kleinian psychoanalytic approach as a contribution to improve the health of patients undergoing bariatric surgery. To that end, we performed a case study based on the analysis of a clinical vignette accompanied by a literature review. We analyzed excerpts of conversations of the psychotherapeutic process of a very obese 53-year-old woman who sought an institution dedicated to the surgical treatment of severe obesity relying on a multidisciplinary approach. After a diagnosis of morbid obesity, an initial psychological evaluation was performed. As an extension, a psychotherapeutic process based on a psychoanalytical approach took place once a week and then later twice a week. Two months after the first meeting, the patient underwent bariatric surgery. To date, the psychotherapeutic process has lasted for three years. As a result, the patient managed to get in touch with her feeling of helplessness associated with a destructiveness factor, which appears in narrative scenes of revenge, envy and jealousy. We conclude that the psychoanalytic process proved to be effective: the patient was able to preserve her constituent affective networks and became less vulnerable to anxiety and impulsivity, favoring reduction of obesity and avoiding situations of suffering such as alcoholism. Our observations confirm some references already mentioned in the literature.

Key words: Morbid obesity, bariatric surgery, psychotherapeutic processes, psychanalysis

(La psychanlyse dans le traitement multidisciplinaire et chirurgie de l'obésité morbide: une étude de cas)

Le but de cette étude est d'évaluer le processus psychothérapeutique à l'aide d'une approche psychanalytique kleinienne pour contribuer à l'amélioration de la santé des patients subissant une chirurgie bariatrique. Pour atteindre ce but, une étude de cas a été développée à partir de la littérature et de l'analyse de vignettes cliniques et on a analysé des extraits de conversations du processus psychothérapeutique d'une femme de 53 ans qui recherchait une institution de traitement chirurgical de l'obésité sévère qui a pour base une approche multidisciplinaire. Après un diagnostic d'obésité morbide, un premier bilan psychologique a été réalisé. En prolongement, le processus psychothérapeutique basé sur une approche psychanalytique a été suivi, une fois par semaine au début et plus tard deux fois par semaine. Deux mois après la première rencontre, la patiente a subi une chirurgie bariatrique. La psychothérapie dure depuis trois ans et a permis à la patiente de faire face à son sentiment de détresse associé au facteur destructif qui 


\section{ARTIGOS}

surgit dans des scènes narratives de vengeance, d'envie et de jalousie. On conclut que le processus psychanalytique s'est avéré efficace: la patiente a réussi à préserver ses réseaux constitutifs affectifs et est moins vulnérable à l'anxiété et à l'impulsivité, favorisant la permanence de la réduction de l'obésité et évitant la formation d'autres situations de souffrance, comme l'alcoolisme. Ces observations confirment certaines références que l'on trouve dans la littérature.

Mots clés: Obésité morbide, chirurgie bariatrique, processus psychothérapeutiques, psychanalyse

(Psicoanálisis en el tratamiento multidisciplinario y quirúrgico de la obesidad mórbida: estudio de caso)

El objetivo del estudio es evaluar el proceso psicoterapéutico a través de un enfoque psicoanalítico kleiniano como contribución a la mejora de la salud de los pacientes sometidos a cirugía bariátrica. Se trata de un estudio de caso basado en el análisis de una viñeta clínica acompañada por una encuesta bibliográfica. Se analizaron extractos de conversaciones del proceso psicoterapéutico de una mujer obesa de 53 años que acudió a una institución dedicada al tratamiento quirúrgico de la obesidad severa con un abordaje multidisciplinario. Después de un diagnóstico de obesidad mórbida, se realizó una evaluación psicológica inicial. Como extensión, se siguió el proceso psicoterapéutico con enfoque psicoanalítico, inicialmente, una vez por semana y después, dos veces por semana. Dos meses después del primer encuentro, la paciente fue sometida a cirugía bariátrica. La psicoterapia ha durado tres años. Como resultado, la paciente se volvió más capaz de conectarse al sentimiento de desamparo asociado al factor destructividad, que aparece en escenas narrativas de venganza, envidia y celos. Se concluyó que el proceso psicoanalítico resultó ser efectivo: la paciente adquirió más condiciones para preservar sus redes afectivas constituyentes y se volvió menos vulnerable a la ansiedad y a la impulsividad, favoreciendo la permanencia de la reducción de la obesidad y evitando la formación de otras situaciones de sufrimiento, como el alcoholismo. Estas observaciones confirman algunas referencias ya mencionadas en la literatura.

Palabras clave: Obesidad mórbida, cirurgía bariátrica, procesos psicoterapéuticos, psicoanálisis 
Citação/Citation: Garrido, P. B., \& Motta, I. F. da (2021, dezembro). Psicanálise no tratamento multidisciplinar e cirúrgico da obesidade mórbida: estudo de caso. Revista Latinoamericana de Psicopatologia Fundamental, 24(4), 638-658. http://dx.doi.org/10.1590/ 1415-4714.2021v24n4p638.8

Editora/Editor: Prof. Dr. Nelson da Silva Jr.

Submetido/Submitted: 13.5.2021 / 5.13.2021 Aceito/Acepted: 30.5.2021/ 5.30.2021

Copyright: (C) 2009 Associação Universitária de Pesquisa em Psicopatologia Fundamental/ University Association for Research in Fundamental Psychopathology. Este é um artigo de livre acesso, que permite uso irrestrito, distribuição e reprodução em qualquer meio, desde que o autor e a fonte sejam citados / This is an open-access article, which permits unrestricted use, distribution, and reproduction in any medium, provided the original authors and sources are credited.

Financiamento/Funding: Este trabalho não recebeu apoio / This work received no funding.

Conflito de interesses/Conflict of interest: Os autores declaram que não há conflito de interesses. / The authors declare that there is no conflict of interest.

\section{Pedro Belarmino Garrido}

Especialista em Psicanálise e mestrando em Psicologia Clínica pelo Departamento de Psicologia Clínica do Instituto de Psicologia da Universidade de São Paulo - USP (São Paulo, SP, Br). Rua Pamplona, 967 01405-200 São Paulo, SP, Br. pbgarrido@hotmail.com hppp://orcid.org/0000-0002-0603-0417

Ivonise Fernandes da MotTa

Doutora em Psicologia Clínica, Departamento de Psicologia Clínica do Instituto de Psicologia da Universidade de São Paulo - USP (São Paulo, SP, Br).

Avenida Prof. Mello Moraes, 1721

05508-030 São Paulo, SP, Br.

ivonise.motta@gmail.com

https://orcid.org/0000-0001-5317-4643

This is an open-access article, which permits unrestricted use, distribution, and reproduction in any medium for non-commercial purposes provided the original authors and sources are credited. 